\title{
A theoretical model of the circuit of empty chemical containers from production to reuse
}

\author{
B. A. Larsen ${ }^{1}$, Y. Villacampa ${ }^{2}$, F. Garcia-Alonso ${ }^{2}$, J. A. Reyes ${ }^{2}$ \\ \& P. Sastre-Vázquez ${ }^{3}$ \\ ${ }^{1}$ Comisión de Investigaciones Científicas de la Provincia de \\ Buenos Aires (CIC), CINEA-FCH, Universidad Nacional del centro de \\ la Provincia de Buenos Aires, Argentina \\ ${ }^{2}$ Applied Mathematics Department, Alicante University, Spain \\ ${ }^{3}$ Mathematics Department, Universidad Nacional del Centro de la \\ Provincia de Buenos Aires, Argentina
}

\begin{abstract}
This paper presents a theoretical model to evaluate the empty agrochemical packaging circuit used in the production of transgenic soya. In order for that, a model has been developed that analyzes the structure and causal relationships of the system. Thanks to this model, it will be possible to understand the retro feeding mechanisms in a time scale. Moreover, there has been shown a graphic representation of the dynamic system that starts in the yield process of the packaging, finishing with its re-use. The mathematical model generated is defined by a group of differential equations. These equations represent the change of the variables defined as level variables in time. The equations have been defined through flow variables that represent the yield rate use, discard and collection of packages. The theoretical model is close to reality and appropriate to simulate situations. During this period a theoretical model has been developed and in earlier stages planned sample taking is presented to obtain data to adjust the theoretical model proposed.
\end{abstract}

Keywords: model, chemical containers reuse.

\section{Introduction}

In Argentina, as in many other Latin American countries, there exists the development of activities that damage the environment as, for instance, the 
advance of the agricultural frontier where the election of the activity by the producers depends on market demands rather than land requirements. As a consequence of this, there is an exhaustion or deterioration of the land, an increase of erosion and desertification, water pollution and progressive loss of existing agricultural areas.

The technological package, consisting of genetically modified soya and direct seeding, which is used almost exclusively in Argentina, has enabled acceleration of agro-productive cycles. However, this technology uses a battery/set of agrochemicals, especially herbicides and insecticides, now added to fungicides and seed treatments (fungicide used in seed treatment) at a high cost. The genetically modified soya is agrochemical dependent. Its development is sustained based on ever increasing quantities of herbicides and insecticides, causing undesired effects on the environment.

Argentina, thanks to the transgenic soya went from being one of the "warehouses of the world" to become the "republic of the soya". The use of soya, genetically modified to tolerate glyphosate-based herbicides, Roundup Ready System (RR) and Monsanto Company [1, 2] let uncontrolled fumigations. This fact has affected human and animal health, the environment and the cultivation for the feeding. The yield of soya has become a strategic monocrop basic for the yield structure of the nation but structurally weak and environmentally unsustainable. Among others, some of its negative effects analysed in this research it is worth to mention the problems generated by the direct seeding system (SD)-soya RR (Roundup Ready)-glyphosate, based on the massive use of traditionally, man has been considered as an entity separate from the environment, giving limited attributes leading to an overexploitation and depletion of systems and natural resources. This fact is closely linked to the development models over the last decades in the vast majority of developed and growing countries [3]. The fact is that, along history, man has been closely connected with nature but its conception about it has been changing, going from visions in which man protected nature to others where it was treated like a predictable and controllable system [4].

This relationship between man and nature is visualized in the development of the human activities on a concrete scenario, the environment, defined as "a space made of many elements: sun light, ground, air, water in all its means (rivers, rain, air moisture), big and small plants and animals, all types and sizes of buildings, artificial light, roads, air-conditioning, machinery, etc." [4].

In this context, agriculture has transformed natural systems in agricultural systems or agro-systems, mainly characterized because of not being selfsustainable, their lack of diversity and resistance, being extremely dependent of the level of use and with short-term goals that make difficult the use of farming practices that tend to maintain a long-term production [5].

The agriculturalization process of the yield systems is a particular and common case of change of land use. On the one hand new agricultural areas are incorporated generating incomes to the yield system; on the other hand, this implies risks in the maintenance of the sustainability of the ecosystems and social systems [6]. It is important to analyse that neither the resilience [7] of the 
environment, the renovation ability of the nutrients or the substitution of labour by machinery among others are taken into consideration. The phenomenon of the soya is an example of an agriculturalization process characterised by a fast growing expansion of the cultivation of transgenic soya in detriment of other cultivations and land uses, generating the aforementioned effects. Due to this, Argentina is one of the countries that rapidly adopted the use of transgenic cultivations, generating a major technological change with environmental and human health related impacts. Due to this, it is important to do a permanent critical analysis of the situation and of the development and implementation of monitoring/control systems [8].

The soyalization process is characterized by the application of certain technology that involves the use of a large amount of agrochemicals; this lead to the utilization of over 200 million litres of glyphosate per year and to an increase in the use of biocides toxic for human health. The agrochemicals used comprehend a variety of chemical products with different absorption means, metabolism, kinetic elimination, action mechanism and toxicity. Despite the active principle, the formulas contain non-inert excipients and solvents since they influence the kinetic toxicity modifying some or all of their steps [9].

People can be more or less exposed to agrochemicals because of their jobs, accidents, food, etc. Due to this, despite the intrinsic toxicity of the agrochemicals, there have to be considered other factors that can increase or decrease the negative effects on man like: dose, means of exposition, age, sex [9].

A common goal in modern agriculture is to be able to control plagues that can affect cultivations in the most rational way. However, it is evident that integrated agriculture does not rejects the utilization of pesticides but underlines the efficient use of those. This way, to reach the goal of this research is it worth to question what to do with these recipients?

Firstly, we have to take into consideration that depending on its proper use they may not become a pollutant or won't be a toxic hazard for the user or for the public in general.

How to proceed then? Once that the pesticide has been loaded in the deposit of the machinery, it is important to give a good cleaning to the package incorporating washing water in the tool of pulverizing as well. This way, there is the financial advantage of using all the purchased product bringing to it its final destination, but avoiding contamination risks as well. Once it's been washed, we will proceed to make useless it through bottom perforation to avoid its potential reuse in any case. After that, it is necessary to contact the storing points that already exist in the region. These centres are linked to Officials Universities or private companies like cooperatives or trader centres. In these storing centres there the compacting process should be carried out to bring the packages to a recycling centre where they will be transformed in low environmental impact products like for instance, pipes for high voltage cables or optic fibre that will be buried underground next to public roads. It is important to realize that, contributing to give these dangerous rural residues a precisely controlled life 
cycle is the right thing to do. The proper re-use of these products will avoid further problems in benefit of the environment and all the population.

The main question of the research is: would it be possible to model the life cycle of empty agrochemical packages for transgenic soya yield? The authors have developed a first approach to the problem concluding that it is possible to model the life cycle of the empty packages generating a Forrester model $[10,11]$.

This model must be generated analysing the process from cradle to re-use.

\section{Methodology}

To achieve our goal a mental model was designed firstly, followed by a causal diagram and finally a Forrester model was developed [11-13], in order to define a group of differential equations to model the process.

It is a tool (fig 2) that shows the structure and causal relationships of a system that will help us to understand its mechanisms in a time scale. The basic elements are the variables or factors and the links or arrows. A variable is a condition, a situation, an action or a decision that can influence in or can be influences by other variables. Another elements are the arrows that represent the casual relationship between two of the variables. This influence can be negative or positive.

Forrester diagrams provide a graphical representation of dynamics systems quantitatively modeling the relationship between the parts by symbols corresponding to a thermodynamic interpretation of the system. It is a representation of the causal diagram in terminology that allows writing equations on the computer in order to validate the model observe the temporary evolution of the variables and do sensitivity analysis.

A feedback loop is a group of variables connected by causality or influence (negative or positive) that form a closed path starting with an initial value and ending with the same variable.

\section{A theoretical model of the circuit of empty chemical containers}

In the following figure 1 the mental model is shown. It is a mechanism that the mind uses to explain how the real world works. Due to the fact that some of the elements of reality are around us and not in our brains, a model should be developed to analyse the problems. One the mental model works, it proceeds to systematize some of its processes or components to increase the efficiency of the process, that is to say, the systematization of a process beginning with the mental model and then studying which parts can be systematized.

\subsection{Modelling of the circuit of empty chemical containers}

The following level variables are considered to explain the process of empty containers from its yield to its reuse:

1. Available containers: AC. Quantity of containers with their content, that is to say number of containers full with the product or chemical agriculture. 


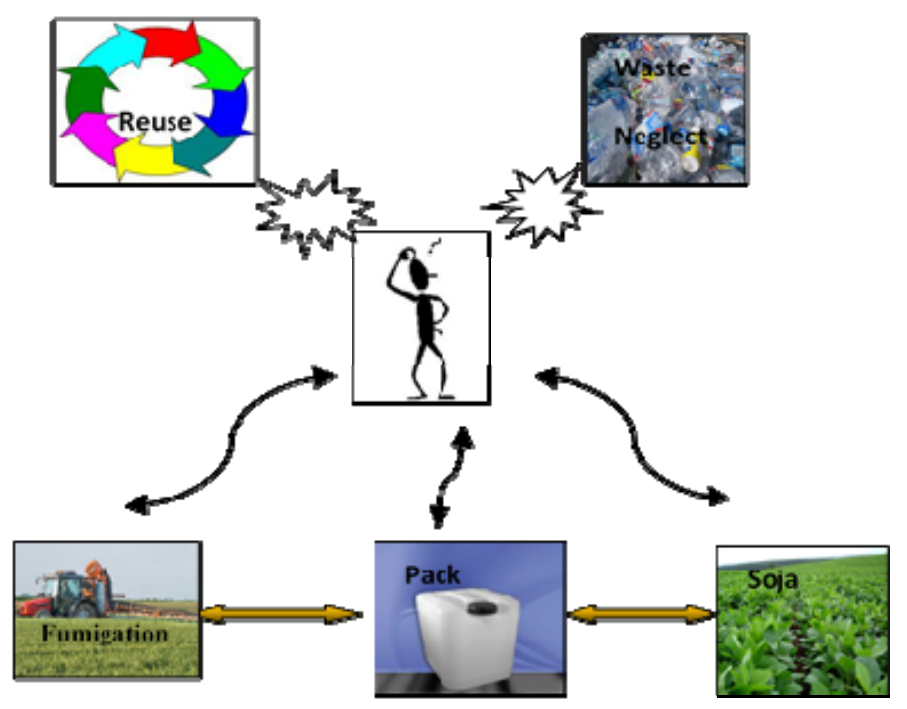

Figure 1: Waste or reuse.

2. Polluted containers: PC. Quantity of containers that don't contain remains of chemical agriculture used in the productive system.

3. Destroyed containers: DC. Quantity of containers destroyed by fire or burial.

4. Recycled containers: RC. Quantity of containers recycled through the triple washing.

The following flow variables are considered to explain the process of empty containers from its yield to its reuse:

1. Yield: Y. Quantity of full containers manufactured by unit of time.

2. Use: U. Amount of full containers used in the productive system by unit of time.

3. Destruction: D. Quantity of polluted containers that are destroyed, for unit of time.

4. Recycled: R. Quantity of polluted containers that become containers recovered, by unit of time.

Furthermore it is used the following auxiliary variables:

1. Yield Rate: PR. Amount of full containers manufactured.

2. Destruction rate: DR. Proportion of containers that leave the contaminated state and pass to the destroyed state.

3. Operational capacity of the machinery: OC. Number of acres that can be sprayed on Labor Day.

4. Duration of the workday: DW. Number of hours a day that can be sprayed.

5. Sequence of goods: SG. Number of operations required to perform the charging of the machinery.

6. Recipe Complexity applied: RC. The number of formulation components, i.e. the variable measures how many chemical components have the recipe.

7. Price of the empty container: PE. Market value of the empty container after being washed. 
8. Distance to the collection center: DC. Number of kilometers until the nearest collection center.

9. Transport cost: TC. The cost of transporting empty containers to the collection center.

10. Surface available for seeding: SAS. Number of hectares available for seeding.

\subsubsection{Sub-model area available for seeding}

For the analysis of this problem a system dynamic model is proposed wherein it is possible to analyze the components of the route taken by packages containing glyphosate. This path relies heavily on the seeding area, so a sub-model is proposed to estimate the acres available for seeding and consequently make medical devices applications.

Two cycles are considered in the model. Cycle 1 represents a restriction of the system due to the availability of land. Cycle 2 is influenced by the amount of land available, less available land meaning increasing costs, causing crop profits to decrease and lower investment.

It is considered the following level variables:

1. Area for Seeding: AS.

2. Seeded area: SA.

It is considered the following flow variables:

1. Harvest 1.

2. Seeding: S.

3. Harvest 2.

In the sub-model it is considered as auxiliary variables:

1. Yield: Y.

2. Profitability: P.

3. Initial Area: IA.

4. New Area: NA.

5. Cost Seeding: CS.

6. Crop Yield: CP.

\subsection{The Causal diagram and Forrester diagram}

The causal diagram represents the causal relationship in the system. Also in the system a sub-model has been generated defining by the area available for seeding. The following figures 2 and 3 represent the causal diagrams that determine relationships for the general study of the system (figure 2) and the specific subsystem (figure 3 ).

Forrester diagram represented in the following figure 4 provides a graphical representation of the dynamic system. That is the relationship between the set of previously defined for the system model of the circuit of empty agrochemical variables, from yield to reuse, further comprising the subsystem defined by the available area for seeding. 


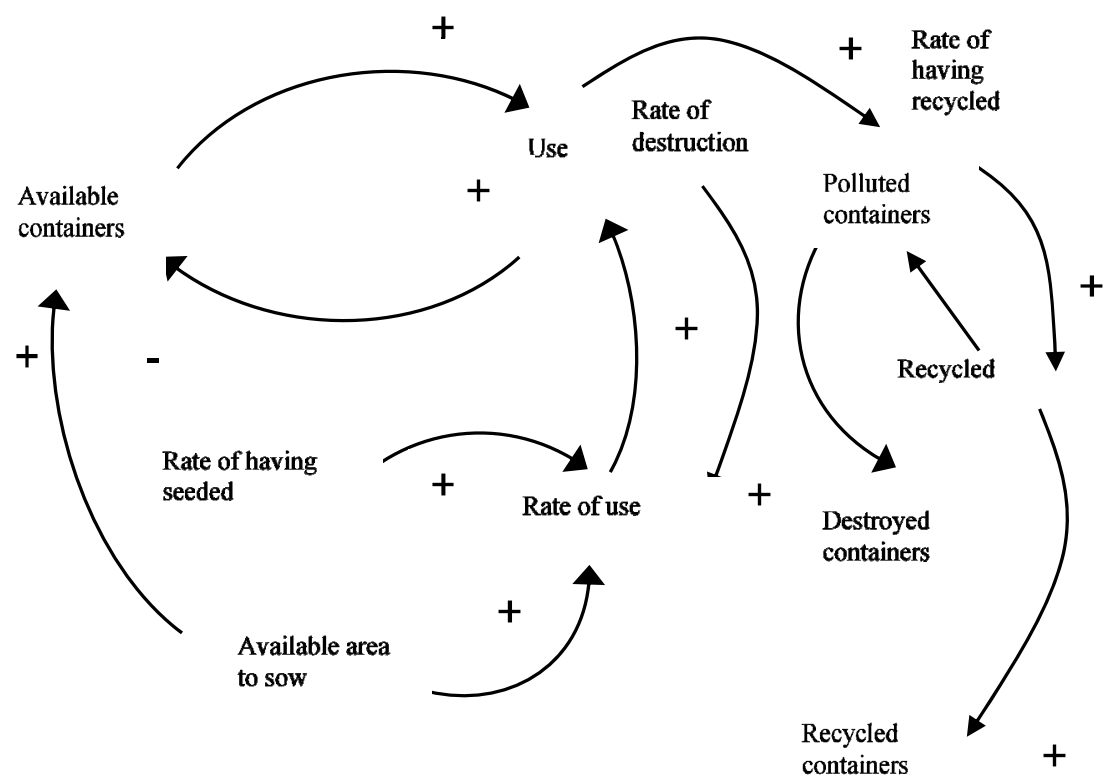

Figure 2: The causal diagrams of the system.

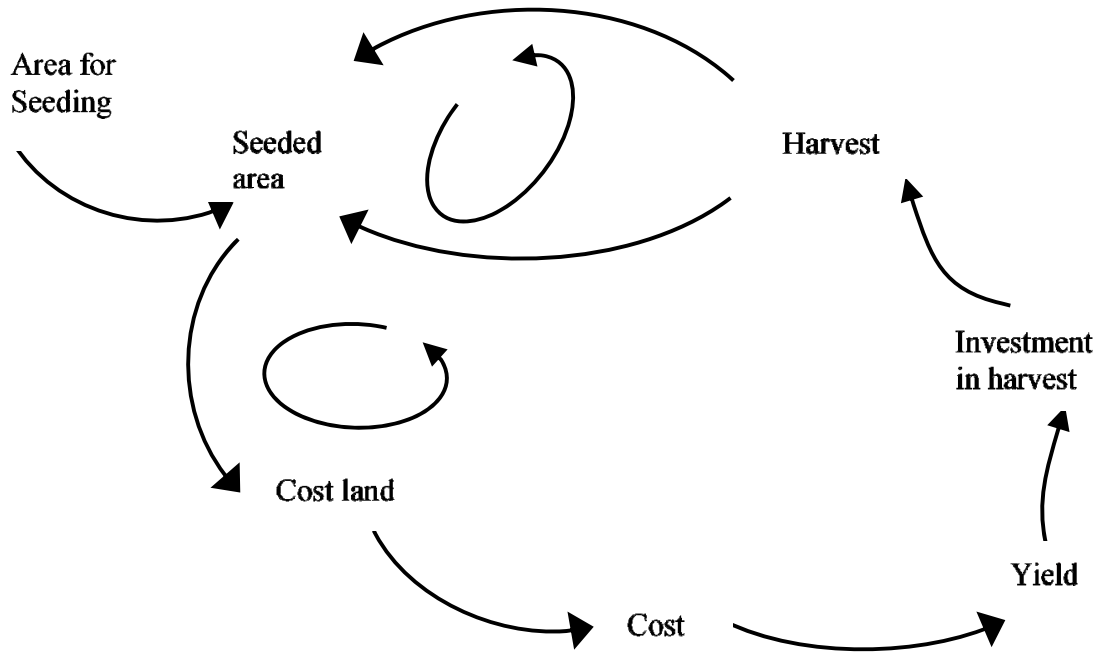

Figure 3: The causal diagrams of the sub-system. 


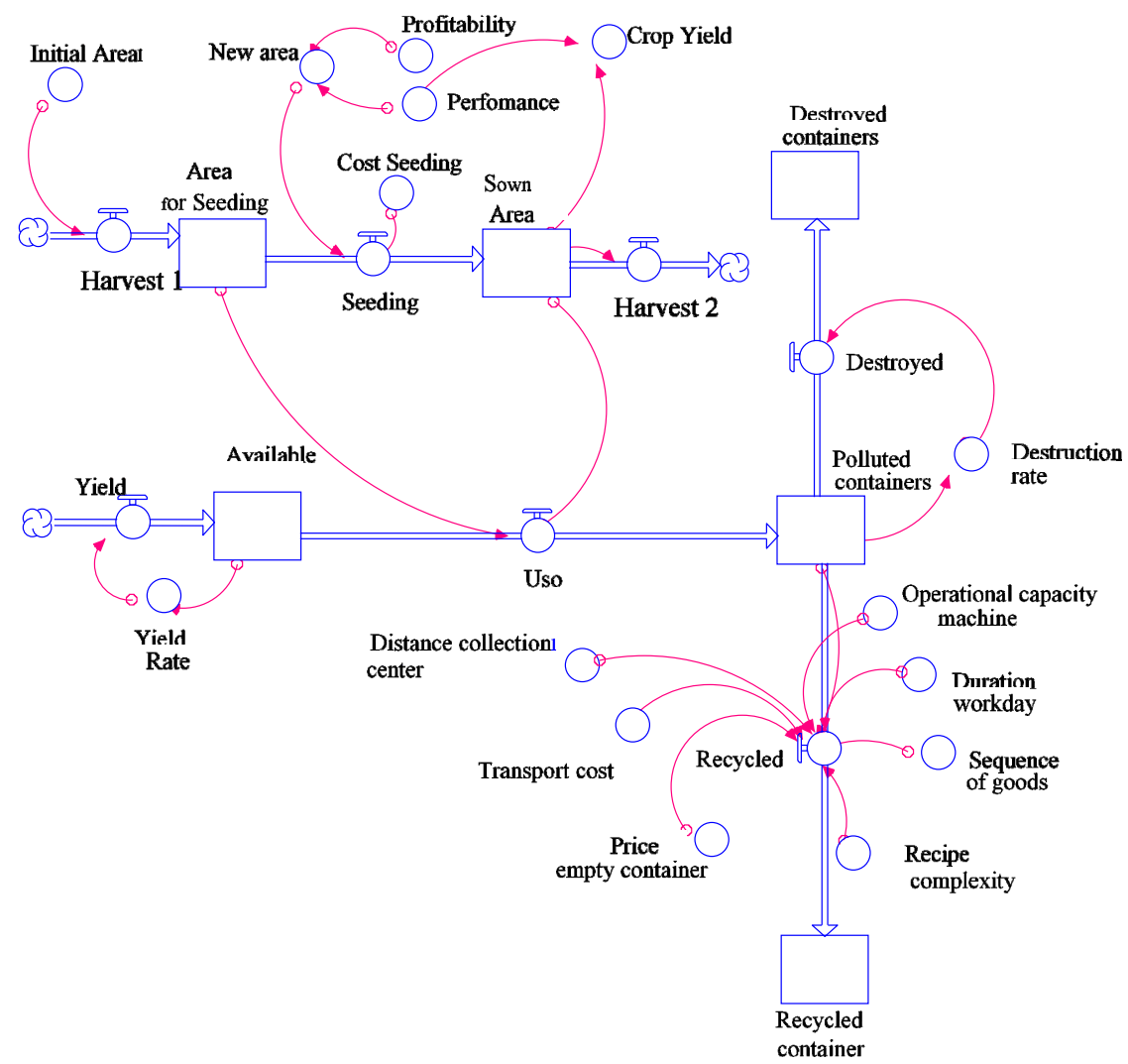

Figure 4: Forrester diagram.

\subsection{Mathematical modelling}

The state equations express the variation over time of the level variables and can be defined from the flow variables. Besides the flow variables can be expressed in terms of other variables.

The following state equations have been defined:

$$
\begin{aligned}
& \frac{d(\mathrm{AC})}{d t}=Y-U \\
& \frac{d(\mathrm{DC})}{d t}=D \\
& \frac{d(\mathrm{PC})}{d t}=U-D-R
\end{aligned}
$$




$$
\frac{d(\mathrm{RC})}{d t}=R
$$

Also, the following relationships or flow equations are considered:

Destruction $=f($ Polluted containers, Destruction rate $)$

Destruction $=$ Destruction rate $*$ Polluted containers

Recycled $=f$ (Polluted containers, Operational capacity of the machinery, Recipe complexity applied, Transport cost, Distance to the collection center, Duration of the workday, Price of the empty container, Sequence of goods)

Yield $=$ Yield rate $*$ Available containers

Use $=f$ (Area for seeding, Sown area, Available containers)

Or in an equivalent way:

Due to the fact that $D=f(P C, D R) ; D=D R * P C$

$R=f(P C, O C, R C, T C, D C, D W, P E, S G)$

$Y=Y R^{*} A C$

$U=f(A S, S A, A C)$

Also, in the sub-model, the following state flow equations have been considered:

$$
\begin{aligned}
& \frac{d(\mathrm{AS})}{d t}=H 1-S \\
& \frac{d(\mathrm{SA})}{d t}=S-H 2
\end{aligned}
$$

\section{Conclusions}

A theoretical model has been defined for the study of the empty agrochemical container cycle, simulating a possible real situation. As is usual, the model does not represent the total reality but does give an approximation of it. The production of the Forrester diagram has made it possible to define a set of differential equations which study, over time, the variation of the level variables. To do this, initially, models for flow variables will have to be generated and analysed, making it possible for the evolution of level variables to be analysed and simulated over time. The study and modelling enables the quantification of the level variables as well as the simulation of their variations, enabling measures to be taken to discover in which levels an improvement in actions is needed. It is therefore possible to define sustainability indicators from the dynamic evolution of the system.

The authors, in their future investigations, and in coordination with the main representatives of the sector, will gather quantitative information for the defined variables in the theoretical model to study the dynamic behaviour of the system. This will furthermore enable the simulation of different scenarios and situations for the better management of the process and contribute to the sustainability of the system 
Moreover, obtaining experimental data will enable the adjustment of the theoretical model proposed in this work

\section{References}

[1] Roundup Ready System. http://www.monsanto.com/weedmanagement/ pages/roundup-ready-system.aspx

[2] Monsanto Company. http://www.monsantoandino.com/

[3] Reboratti, C. y Sabalain, C., "El mundo rural de Argentina: modernización, fragmentación y crisis" en Segrelles Serrano, José A. Agricultura y espacio rural en Latioamérica y España (Madrid: Ministerio de Agricultura), 2002.

[4] Reboratti, C., "Agricultura, Sociedad y Ambiente Miradas y Conflictos". Carlos Reboratti (Coordinador) Responsable editorial: Guillermo Neiman. Bs.As. Argentina, 2000.

[5] Stoskopf, N.C., "Cereals in understanding crop Production". Published by Reston Co. USA. 1981.

[6] Paruelo, J.M.; Guerschman, J.P.; Piñeiro, G.; Jobbágy, E.G.; Verón, S.R.; Baldi, G. y Baeza, S. Cambios en el uso de la tierra en Argentina y Uruguay. Agrociencia. Vol. X, N², pp. 47-61, 2006.

[7] Holling, C.S., Regime Shifts, Resilience, and Biodiversity in Ecosystem Management. Annual Review of Ecology, Evolution, and Systematics. Vol. 35, pp. 557-581, 2004.

[8] Gallopín, G.C., "La sostenibilidad ambiental del desarrollo en Argentina: tres futuros". Serie Medio Ambiente y Desarrollo No. 91, Sustainable Development and Human Settlements Division, ECLAC, Santiago, Chile, 2004.

[9] Torriggino, A. Agroquímicos y salud, 2005. Available in: http://www.oni.escuelas.edu.ar/2005/ENTRE_RIOS/980/bibliog.html

[10] Aracil, J., "Introducción a la Dinámica de Sistemas". Alianza Editorial. ISBN 84-206-8058, 1986.

[11] Sterman, John D., "Business Dynamics". Irwin McGraw-Hill. ISBN: 007238915X, 2000.

[12] Forrester, J. W., "Industrial Dynamics". Pegasus Communications. ISBN 1-883823-36-6, 1961.

[13] Sterman, J. D., System dynamics modeling. California management review. Vol. 4, No 43, pp. 8-25, 2001. 